\title{
Inhibitory system overstimulation plays a role in the pathogenesis of neuromuscular and neurological diseases: a novel hypothesis [version 1; peer review: 2 approved]
}

\author{
Bert Tuk ${ }^{1,2}$ \\ 1'Leiden Academic Center for Drug Research (LACDR), Leiden University, Leiden, 2333 CC, The Netherlands \\ ${ }^{2}$ Ry Pharma, Hofstraat 1, Willemstad, 4797 AC, The Netherlands
}

V1 First published: 20 Jun 2016, 5:1435

https://doi.org/10.12688/f1000research.8774.1

Latest published: 19 Aug 2016, 5:1435

https://doi.org/10.12688/f1000research.8774.2

\section{Abstract}

Based upon a thorough review of published clinical observations regarding the inhibitory system, I hypothesize that this system may play a key role in the pathogenesis of a variety of neuromuscular and neurological diseases. Specifically, excitatory overstimulation, which is commonly reported in neuromuscular and neurological diseases, may be a homeostatic response to inhibitory overstimulation. Involvement of the inhibitory system in disease pathogenesis is highly relevant, given that most approaches currently being developed for treating neuromuscular and neurological diseases focus on reducing excitatory activity rather than reducing inhibitory activity.

\section{Keywords}

Neuromuscular disease, neurodegeneration, ALS , FTD , Alzheimer's disease, Parkinson's disease, Huntington's disease, Primary Lateral Sclerosis

\section{Open Peer Review \\ Approval Status}

1

2

version 2

(revision)

19 Aug 2016

version 1

20 Jun 2016

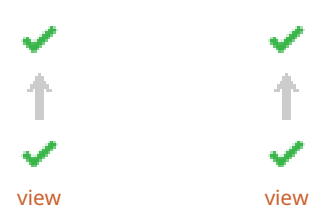

1. Janet Hoogstraate, Valneva Sweden $A B$,

Stockholm, Sweden

Stockholm Brain Institute, Stockholm,

Sweden

2. Willem M de Vos, Wageningen University,

Wageningen, The Netherlands

Any reports and responses or comments on the article can be found at the end of the article. 
Corresponding author: Bert Tuk (bert.tuk@rypharma.com)

Competing interests: BT has filed a patent application on the treatment of neuromuscular and neurologic diseases with therapies that reduce inhibitory overstimulation, and founded Ry Pharma, a company that aims to develop such therapies.

Grant information: The author(s) declared that no grants were involved in supporting this work.

Copyright: $\odot 2016$ Tuk B. This is an open access article distributed under the terms of the Creative Commons Attribution License, which permits unrestricted use, distribution, and reproduction in any medium, provided the original work is properly cited.

How to cite this article: Tuk B. Inhibitory system overstimulation plays a role in the pathogenesis of neuromuscular and neurological diseases: a novel hypothesis [version 1; peer review: 2 approved] F1000Research 2016, 5:1435

https://doi.org/10.12688/f1000research.8774.1

First published: 20 Jun 2016, 5:1435 https://doi.org/10.12688/f1000research.8774.1 


\section{The clinical manifestations of neuromuscular and neurological diseases have high overlap}

The pathogenesis of most neuromuscular and neurological diseases is poorly understood, despite their devastating impact on quality of life and the fact that they were first described more than a century ago. Clinically, neuromuscular diseases manifest as progressive muscle weakness together with a general set of motor symptoms, including speech-related difficulties, impaired mobility, and reduced fine motor skills ${ }^{1}$. In contrast, neurological diseases manifest primarily as a progressive decline in cognitive function. Interestingly, the clinical manifestations of neuromuscular and neurological diseases also overlap; this overlap is summarized in Table 1 for primary lateral sclerosis (PLS), amyotrophic lateral sclerosis (ALS), ALS with frontotemporal dementia (ALSFTD), FTD with ALS (FTD-ALS), FTD, Alzheimer's disease, Parkinson's disease, and Huntington's disease ${ }^{1-29}$. The clinical features shared between the neuromuscular disease ALS and the neurological disease FTD exemplify this overlap, as late-stage ALS can lead to the manifestation of FTD; conversely, FTD can progress to ALS, leading to the manifestation of FTD-ALS ${ }^{2-8}$.

\section{Elevated glutamate levels are involved in the pathogenesis of both neuromuscular and neurological diseases}

A key observation gleaned from analyzing Table 1 is the finding that glutamate levels are increased in the cerebrospinal fluid (CSF) of patients in all eight diseases ${ }^{22-29}$. Glutamatergic (i.e., excitatory) overstimulation induces excitotoxicity in cultured neurons and is believed to be an important factor in the pathogenesis of both neuromuscular and neurological diseases ${ }^{22-29}$. Glutamate-induced excitotoxicity can result in the decay of neuronal pathways that innervate muscles and other physiological systems ${ }^{22-29}$. This decay gives rise to the loss of physiological function and is considered to lead to the clinical manifestations that present with both neuromuscular disease and neurological disease ${ }^{22-29}$. I hypothesize that these increased glutamate levels are actually a homeostatic response to an overstimulated inhibitory system. This novel hypothesis is based upon the observation that the clinical findings in neuromuscular and neurological diseases can be explained by inhibitory activity, as discussed below.

\section{Despite increased glutamate levels, patients with neuromuscular and neurological diseases do not have increased epileptic activity}

Since they were first diagnosed more than a century ago, the clinical manifestations of neuromuscular and neurologic diseases have been well described. Strikingly, however, the consequences of one key clinical feature of these diseases - the absence of an elevated risk of seizure activity — have been largely overlooked.

This is exemplified for ALS in which a broad, detailed retrospective study of the medical records of 657 ALS patients revealed that none of the patients presented with epilepsy as a co-morbid condition". Moreover, a thorough search of PubMed for articles published from 1966 through 2016 using the key words "seizure" or "epilepsy" in combination with "amyotrophic lateral sclerosis" or "ALS" confirms the striking absence of epilepsy and/or seizures in ALS patients. This finding is consistent with the absence of seizures and/or epilepsy in review articles describing the clinical manifestation of $\mathrm{ALS}^{2-6}$.
A key observation that makes the absence of seizure activity in ALS even more remarkable is increased glutamate levels in the cerebrospinal fluid (CSF) of patients with ALS; on average, glutamate levels in the CSF of ALS patients are increased by $100 \%$, and some ALS patients can have an increase of up to $800 \%{ }^{23}$. Importantly, increased glutamate levels are generally associated with epileptic seizures ${ }^{30,31}$. Thus, given the increased glutamate levels typically measured in the CSF of ALS patients, one would logically expect that the prevalence of epilepsy in ALS patients should be elevated relative to the general population. However, despite this expectation, epileptic seizures are simply not reported among ALS patients.

Strikingly, in addition to ALS, none of the other seven diseases listed in Table 1 typically present with an increased risk of epileptic seizures, either ${ }^{2-15}$, even though all eight diseases present with elevated glutamate levels in the $\mathrm{CSF}^{22-29}$.

\section{Despite elevated glutamate levels, muscles in neuromuscular and neurological patients are inhibited}

A second key observation is that neuromuscular and neurological diseases have an inhibitory effect on muscle function, rather than being excitatory. The diseases listed in Table 1 are characterized by muscle inhibition, even though glutamate-which, as discussed above, is generally increased in these diseases-is the major neurotransmitter that drives muscle activation by increasing the firing rate of motor neurons. Remarkably, however, despite having increased levels of glutamate in the CSF, patients with neuromuscular and neurological diseases do not have increased muscle activation. This is exemplified most clearly by ALS, a disease with highly elevated glutamate levels ${ }^{22,23}$ and complete muscle inhibition in the end stages. Although fasciculation and/or cramps can be observed in ALS patients ${ }^{2-4}$, these features occur in debilitated muscles as they progress from a fully functional state toward a fully inhibited state.

One possible explanation for these seemingly contradictory findings is a second system that exerts strong anticonvulsive activity in both neuromuscular and neurological diseases. Importantly, such a system should be as widespread throughout the nervous system as the glutamatergic system, and the inhibitory system fulfills these requirements. Specifically, the inhibitory (GABA) system i) functions to oppose the glutamatergic excitatory neurotransmitter system, ii) inhibits muscle activity by reducing the firing rate of motor neurons, and iii) exerts strong anticonvulsive activity ${ }^{26,30,31}$.

\section{The clinical features of neuromuscular and neurological diseases can be induced by increasing inhibitory activity}

A third key observation is that the clinical manifestations of neuromuscular and neurological diseases can be induced using interventions that increase GABAergic (i.e., inhibitory) activity (Table 2). For example, activating the GABAergic inhibitory system using benzodiazepines can render healthy muscles dysfunctional $^{32,33}$. In addition, fatal respiratory depression can be induced by administering an overdose of the GABAergic benzodiazepine midazolam ${ }^{34}$. Chronically stimulating the inhibitory system can cause chronic muscle disuse that can lead to muscle atrophy ${ }^{35}$. Moreover, ingestion of alcohol (another GABAergic inhibitory compound $^{36}$ ) impedes coordination and causes slurred speech 
Table 1. Overview of the clinical manifestations in eight progressive neuromuscular and neurological diseases ${ }^{1-29}$.

\begin{tabular}{|c|c|c|c|c|c|c|c|c|}
\hline Clinical manifestation & $\stackrel{\sim}{\alpha}$ & $\frac{\infty}{4}$ & $\frac{0}{\frac{1}{4}}$ & $\begin{array}{l}\frac{3}{4} \\
\frac{1}{5} \\
\end{array}$ & 믄 & 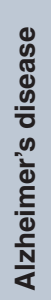 & 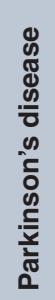 & 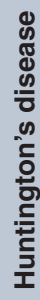 \\
\hline Elevated glutamate CSF levels & $\sqrt{ }$ & $\sqrt{ }$ & $\sqrt{ }$ & $\sqrt{ }$ & $\sqrt{ }$ & $\sqrt{ }$ & $\sqrt{ }$ & $\sqrt{ }$ \\
\hline Elevated epileptic activity & - & - & - & - & - & - & - & - \\
\hline Dysphagia & $\sqrt{ }$ & $\sqrt{ }$ & $\sqrt{ }$ & $\sqrt{ }$ & $\sqrt{ }$ & $\sqrt{ }$ & $\sqrt{ }$ & $\sqrt{ }$ \\
\hline Dysarthria & $\sqrt{ }$ & $\sqrt{ }$ & $\sqrt{ }$ & $\sqrt{ }$ & $\sqrt{ }$ & $\sqrt{ }$ & $\sqrt{ }$ & $\sqrt{ }$ \\
\hline Eye movement difficulties & $\sqrt{ }$ & $\sqrt{ }$ & $\sqrt{ }$ & $\sqrt{ }$ & $\sqrt{ }$ & $\sqrt{ }$ & $\sqrt{ }$ & $\sqrt{ }$ \\
\hline Bladder dysfunction & $\sqrt{ }$ & $\sqrt{ }$ & $\sqrt{ }$ & $\sqrt{ }$ & $\sqrt{ }$ & $\sqrt{ }$ & $\sqrt{ }$ & $\sqrt{ }$ \\
\hline Gastrointestinal dysfunction & $\sqrt{ }$ & $\sqrt{ }$ & $\sqrt{ }$ & $\sqrt{ }$ & $\sqrt{ }$ & $\sqrt{ }$ & $\sqrt{ }$ & $\sqrt{ }$ \\
\hline Cognitive dysfunction & - & $\sqrt{ }$ & $\sqrt{ }$ & $\sqrt{ }$ & $\sqrt{ }$ & $\sqrt{ }$ & $\sqrt{ }$ & $\sqrt{ }$ \\
\hline Rest tremor & - & - & - & - & - & - & $\sqrt{ }$ & - \\
\hline Respiratory depression & $\sqrt{ }$ & $\sqrt{ }$ & $\sqrt{ }$ & $\sqrt{ }$ & - & $\sqrt{ }$ & $\sqrt{ }$ & $\sqrt{ }$ \\
\hline Coordination difficulties & $\sqrt{ }$ & $\sqrt{ }$ & $\sqrt{ }$ & $\sqrt{ }$ & - & $\sqrt{ }$ & $\sqrt{ }$ & $\sqrt{ }$ \\
\hline Impaired muscle function & $\sqrt{ }$ & $\sqrt{ }$ & $\sqrt{ }$ & $\sqrt{ }$ & - & $\sqrt{ }$ & $\sqrt{ }$ & $\sqrt{ }$ \\
\hline Severe muscle wasting & - & $\sqrt{ }$ & $\sqrt{ }$ & $\sqrt{ }$ & - & - & - & - \\
\hline
\end{tabular}

Table 2. The clinical manifestations of neuromuscular and neurological diseases can be induced by administering compounds that increase inhibitory activity ${ }^{31-54}$.

\begin{tabular}{|l|l|}
\hline Clinical manifestation & \multicolumn{1}{c|}{ Role of the inhibitory system } \\
\hline Dysphagia & $\begin{array}{l}\text { GABAergic compound administration leads to dysphagia that can be reversed by the administration of } \\
\text { GABA antagonists }\end{array}$ \\
\hline Dysarthria & GABAergic alcohol ingestion can lead to dysarthria \\
\hline Eye movement dysfunction & GABAergic benzodiazepine administration can lead to eye movement dysfunction \\
\hline Bladder dysfunction & GABAergic activity can lead to bladder dysfunction \\
\hline Bowel dysfunction & GABAergic activity can lead to bowel dysfunction \\
\hline Cognitive dysfunction & GABAergic benzodiazepine administration can lead to increases in dementia scores \\
\hline Dementia & Long-term GABAergic alcohol ingestion can lead to alcohol-related dementia \\
\hline Respiratory depression & GABAergic benzodiazepine administration can lead to respiratory depression \\
\hline Coordination difficulties & GABAergic alcohol ingestion can lead to coordination difficulties \\
\hline Muscle dysfunction & GABAergic benzodiazepine administration can lead to muscle dysfunction \\
\hline Muscle blockade & $\begin{array}{l}\text { GABAergic benzodiazepine administration can lead to muscle blockade even causing respiratory } \\
\text { depression-related fatalities }\end{array}$ \\
\hline Muscle atrophy & $\begin{array}{l}\text { GABAergic benzodiazepine administration can lead to muscle blockades that leads to muscle disuse that } \\
\text { is associated with muscle atrophy }\end{array}$ \\
\hline Muscle wasting & $\begin{array}{l}\text { GABAergic benzodiazepine administration can lead to muscle blockades that leads to muscle disuse that } \\
\text { is associated with loss of muscle mass }\end{array}$ \\
\hline GABAergic activity can account for the faster disease progression observed in clinical trials where ALS \\
\hline patients are treated with GABAergic compounds
\end{tabular}


(dysarthria), which are features of neuromuscular and neurological diseases. In cats, dysphagia (difficulty swallowing) can be either induced or reversed using GABA agonists or GABA antagonists, respectively $^{37}$. Dysphagia has also been reported in humans following the administration of either benzodiazepines ${ }^{38-40}$ or alcohol ${ }^{41}$. Administration of benzodiazepines reduces voluntary saccadic eye movement function ${ }^{42}$ and increases EEG beta-wave activity ${ }^{42}$, clinical manifestations that also occur in neuromuscular and neurological diseases ${ }^{18,43,44}$. Increased GABAergic inhibitory activity can also cause bladder ${ }^{45,46}$ and gastrointestinal dysfunction ${ }^{47,48}$, both of which can manifest in neuromuscular and neurological diseases ${ }^{19-21}$. Strikingly, GABAergic activity can also explain the overlapping clinical manifestations between Alzheimer's disease and alcoholrelated dementia ${ }^{49}$, and it can explain the increase in dementialike symptoms observed after the administration of the benzodiazepine diazepam ${ }^{50}$. Inhibitory activity can also explain neuromuscular and neurological disease predisposition in the elderly, as the sensitivity to GABA inhibitory activity is known to increase with age ${ }^{51}$. Finally, GABAergic activity has been implicated in cognitive dysfunction ${ }^{52-54}$, which is a hallmark feature of neurological diseases and is often observed in late-stage neuromuscular disease $^{2-7}$. Taken together, these findings support the notion that the clinical features associated with neuromuscular and neurological diseases can be induced by activating the inhibitory system.

\section{Modulating inhibitory activity can explain the progression of ALS in clinical trials}

In addition to mimicking the majority of clinical manifestations observed in neuromuscular and neurological diseases, GABAergic activity can also explain the more rapid disease progression of ALS reported in clinical trials in which patients received GABAergic compounds. For example, in two trials gabapentin increased the rate of disease progression in patients with $\mathrm{ALS}^{55}$. A similar effect was reported in patients with ALS who received the GABAergic compound topiramate ${ }^{56}$. GABAergic action can also explain the more rapid disease progression of ALS in clinical trials in which patients received the antibiotic minocycline ${ }^{57}$, which has GABAergic activity $^{58}$. Finally, GABAergic involvement can explain the observed efficacy of the taurine conjugate form of ursodeoxycholic acid (UDCA) in ALS patients ${ }^{59}$, as UDCA inhibits GABAergic action ${ }^{60}$.

\section{Neuromuscular and neurological manifestations can be attributed to simple inhibition and/or recurrent inhibition}

A fourth key observation is that the clinical manifestations associated with neuromuscular and neurological diseases can be attributed to the activity of either simple inhibition (SI) or recurrent inhibition (RI) pathways. Specifically, I postulate that differences between muscles under the control of SI and/or RI underlie the important-yet poorly understood-manifestations of neuromuscular and neurological diseases.

The inhibitory system functions via both $\mathrm{SI}$ and $\mathrm{RI}^{61}$. The RI system controls physiological functions that play a role in counteracting gravitational forces and other external forces acting on the body. During locomotion and/or to counteract the effects of gravity, RI uses a negative inhibitory feedback loop (Figure 1), thereby providing muscles with additional, stabilizing input. Therefore, muscles

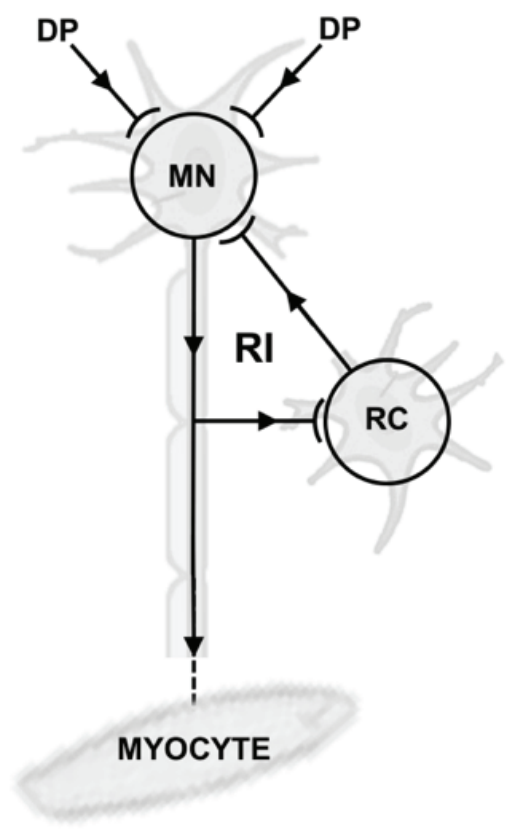

Figure 1. Schematic overview of recurrent inhibition. With recurrent inhibition $(\mathrm{RI})$, input from descending pathways (DP) reaches the motor neuron ( $\mathrm{MN})$. In response, the $\mathrm{MN}$ activates the target myocyte; in addition, the $\mathrm{MN}$ also activates Renshaw cells (RC), which then inhibit the motor neuron through a negative feedback loop.

involved in movement and lifting heavy objects are subject to RI. Examples of RI-innervated muscles include the limb and thorax muscles, as well as the neck muscles that control head movement.

In contrast, neuronal pathways that do not play a role in locomotion or counteracting gravity selectively utilize $\mathrm{SI}^{61}$. Examples of SI-innervated muscles include facial, speech, pharyngeal, and eye muscles, as well as muscles that are involved in bowel and bladder function.

Table 3 summarizes the involvement of SI and RI in the principal clinical manifestations of neuromuscular and/or neurological diseases. A close examination of Table 3 reveals that one set of muscles - namely, the respiratory muscles - is innervated by both SI and RI pathways ${ }^{61,62}$. This dual innervation arises because the respiratory muscles play a role in both respiratory function and maintaining body posture ${ }^{61}$.

\section{SI and RI involvement can account for various onset manifestations in ALS}

Strikingly, the categorization between SI-innervated and RIinnervated muscles coincides with the categorization of muscles affected in limb-onset ALS, bulbar-onset ALS, and respiratoryonset ALS. Approximately 70\%, 25\%, and 5\% of ALS patients present initially with limb involvement (limb-onset ALS), bulbar symptoms (bulbar-onset ALS), or respiratory symptoms (respiratory-onset ALS), respectively ${ }^{2}$, and this difference in onset can be explained by differences in SI versus RI involvement (Table 4). 
Patients with both SI and RI involvement at the onset of disease present with respiratory-onset ALS. In contrast, patients with primarily SI involvement present with bulbar-onset ALS, whereas patients with primarily RI involvement present with limb-onset ALS (see Table 4). Thus, SI and RI differentiation can account for this difference in ALS onset.

\section{SI versus RI involvement can account for differences in life expectancy among patients with ALS}

The differential involvement of the SI or RI system can also explain the observed differences in life expectancy between patients who present with limb-onset, bulbar-onset, or respiratory-onset ALS. Specifically, patients with respiratory-onset ALS generally have the shortest life expectancy following diagnosis ${ }^{4}$. As discussed above, increased activity of both the SI and RI pathways leads to fatal respiratory depression, the principal cause of early death in patients with ALS

Increased activity of either the SI or RI pathway-but not bothcan also lead to respiratory depression, albeit not to fatal levels. Under these conditions, respiratory function, though impaired, can be maintained by either SI or RI pathway activity. However, due to impaired respiratory function resulting from either SI or RI overstimulation (see Table 4), these patients can die from dysphagia-related malnutrition and/or aspiration pneumonia. Thus, patients with either SI or RI involvement—but not both—generally live longer than patients with both SI and RI involvement. Importantly, this observation can also explain why patients with motor

Table 3. Summary of neuronal pathways involved in neuromuscular and/or neurological diseases and their innervation by either simple inhibition (SI) or recurrent inhibition (RI) ${ }^{61}$.

\begin{tabular}{|c|c|l|}
\hline SI & RI & Neuronal pathways involved in neuromuscular and/or neurological diseases \\
\hline$\sqrt{ }$ & & Neuronal pathways controlling muscles involved in dysphagia \\
\hline$\sqrt{ }$ & & Neuronal pathways controlling muscles involved in dysarthria \\
\hline$\sqrt{ }$ & & Neuronal pathways controlling muscles involved in bowel function \\
\hline$\sqrt{ }$ & & Neuronal pathways controlling muscles involved in bladder function \\
\hline$\sqrt{ }$ & & Neuronal pathways controlling muscles involved in eye movement \\
\hline$\sqrt{ }$ & & Neuronal pathways controlling cognitive function \\
\hline$\sqrt{ }$ & & Neuronal pathways controlling respiratory muscles not involved in maintaining body posture \\
\hline & $\sqrt{ }$ & Neuronal pathways controlling respiratory muscles involved in maintaining body posture \\
\hline & $\sqrt{ }$ & Neuronal pathways controlling limb muscles involved in body locomotion or maintaining body posture \\
\hline
\end{tabular}

Table 4. Limb-onset, bulbar-onset, and respiratory-onset ALS can be differentiated based on targets that are innervated by simple inhibition (SI) and/or recurrent inhibition (RI).

\begin{tabular}{|c|c|c|c|}
\hline SI & $\mathbf{R I}$ & Projection target of affected neurons & ALS onset type \\
\hline & $\sqrt{ }$ & Distal upper-limb muscles & \multirow{4}{*}{ Limb-onset ALS } \\
\hline & $\sqrt{ }$ & Proximal upper-limb muscles & \\
\hline & $\sqrt{ }$ & Distal lower-limb muscles & \\
\hline & $\sqrt{ }$ & Proximal lower-limb muscles & \\
\hline & $\sqrt{ }$ & Respiratory muscles involved in maintaining body posture & \multirow[t]{2}{*}{ Respiratory-onset ALS } \\
\hline$\sqrt{ }$ & & Respiratory muscles not involved in maintaining body posture & \\
\hline$\sqrt{ }$ & & Speech muscles & \multirow{9}{*}{ Bulbar-onset ALS } \\
\hline$\sqrt{ }$ & & Swallowing muscles & \\
\hline$\sqrt{ }$ & & Tongue, mouth, cheek, and palate muscles & \\
\hline$\sqrt{ }$ & & Bladder muscles & \\
\hline$\sqrt{ }$ & & Gastrointestinal muscles & \\
\hline$\sqrt{ }$ & & Eye muscles & \\
\hline$\sqrt{ }$ & & Facial movements & \\
\hline$\sqrt{ }$ & & Emotional function & \\
\hline$\sqrt{ }$ & & Cognitive function & \\
\hline
\end{tabular}


neuron diseases at either end of the SI/RI spectrum-for example, primary lateral sclerosis, progressive muscular atrophy, progressive bulbar palsy, or pseudobulbar palsy-have a longer life expectancy than patients with $\mathrm{ALS}^{4}$, which lies in the middle of the spectrum.

\section{The SI and RI pathways can explain both the progression of ALS into FTD and the progression from FTD into ALS}

Differences between the effects of SI versus RI involvement can explain the fact that although ALS and FTD generally involve two distinct systems, these two diseases have a certain degree of overlap with respect to their clinical manifestations (see Table 1). Thus, if RI overstimulation precedes SI involvement, the patient can present with an initial diagnosis of ALS and can progress to ALSFTD, a common manifestation of cognitive dysfunction observed in $20-50 \%$ of patients with late-state ALS patients ${ }^{2-7}$. Alternatively, if SI overstimulation precedes RI involvement, FTD is the initial diagnosis, and the disease can progress to FTD-ALS when the RI pathway becomes involved. Moreover, the division between SI and RI can also explain the overlap between subcategories of ALS and FTD with respect to impaired cognition and altered behavior that involve SI, and movement dysfunction that involves RI.

\section{Differential involvement of SI and RI can account for the wide variety of clinical manifestations in ALS}

Although it is generally considered one disease, ALS can present with a wide spectrum of clinical manifestations, and this spectrum can be explained by the involvement of SI and/or RI pathways. For example, SI overstimulation can lead to bulbar, cognitive, and frontotemporal dementia-related manifestations without causing severe muscle wasting or respiratory malfunction (for example, as observed in patients with bulbar-onset ALS). On the other hand, RI overstimulation can lead to locked-in syndrome, a state in which the patient retains cognitive and emotional function but becomes "locked" in their body, with all of the muscles that counteract gravity and other external forces rendered essentially dysfunctional. Interestingly, the only muscles that are spared in locked-in syndrome-and the only way in which end-stage patients can communicate with the outside world-are the muscles that control eye movement. This is an important observation, given that the muscles that control eye movement are not controlled by RI pathways (see Table 3). The distinction between SI and RI can also explain the observation that some patients with ALS have fully intact cognitive and emotional functions even after their muscles involved in countering gravity have become dysfunctional; the most famous example of this phenomenon is Stephen Hawking, who despite being diagnosed with ALS in his early twenties remains active as a prominent theoretical physicist, now in his seventies ${ }^{63}$.

\section{Split-hand syndrome in ALS can be explained by differential innervation of SI and RI pathways}

Split-hand syndrome is common among patients with ALS ${ }^{64}$. With split-hand syndrome, the abductor pollicis brevis (APB) and first dorsal interosseous (FDI) muscles are affected, whereas the abductor digiti minimi (ADM) muscle is relatively spared. This syndrome is particularly puzzling, as these muscles are innervated identically, yet are affected differently ${ }^{64}$. I propose that split-hand syndrome can be attributed to differences in the extent to which RI pathways innervate the hand muscles that are involved in precision gripping, versus muscles that also play a role in power gripping. With precision gripping (for example, when using a pen), the fingers and thumb press against each other; this type of grip does not involve lifting a relatively heavy object ${ }^{65}$. In contrast, power gripping (for example, when gripping a hammer or lifting a heavy pan) uses the fingers, palm, and thumb to clamp down on a heavy object in order to lift and control the object ${ }^{65}$. Napier ${ }^{65}$ used this distinction to distinguish muscle activities that are involved in body locomotion and/or posture from muscle activities that do not involve locomotion or posture. Thus, Napier's separation also categorizes muscle activities into those that are controlled by RI and those that are controlled by SI. Because the primary function of the ADM muscle is to move the little finger (i.e., the fifth digit) away from the hand, the ADM muscle is only involved in precision gripping and would therefore not be affected by RI overstimulation. This is consistent with the reported absence of RI in motor neurons that innervate the $\mathrm{ADM}^{61,66}$. On the other hand, the APB and FDI muscles are involved in the opposition and extension of the thumb and are therefore involved in power gripping ${ }^{61}$; thus, these two muscles are affected by RI overstimulation.

\section{Parkinson's disease rest tremors can be attributed to differences between SI and RI involvement}

In Parkinson's disease, rest tremors arise from involuntary rhythmic oscillatory movements of a body part at rest; these tremors stop when the patient actively moves the affected body part. The pathways that underlie rest tremors have not been identified, and the fact that rest tremors resolve during voluntary movement is one of the most puzzling observations associated with Parkinson's disease $^{67}$. However, because these tremors occur at rest (and not during active motion or while countering the effects of gravity), the muscles involved are likely innervated by SI pathways, making rest tremors an SI-specific phenomenon. This is further illustrated by the finding that rest tremors resolve when the affected body part becomes involved in locomotion, stance, or maintaining inertia $^{67}$, actions that involve muscles that are controlled by $\mathrm{RI}^{61}$. Interestingly, the hand tremor that is most specific to patients with Parkinson's disease-the so-called "pill-rolling tremor"-also results from muscles that are innervated solely by SI pathways. Specifically, the pill-rolling tremor involves muscles that play a role in precision gripping but not in power gripping, a distinction that is highly reminiscent of split-hand syndrome in ALS (see above). Furthermore, involvement of the inhibitory system in Parkinson's disease rest tremors is supported by the observation that the rest tremors observed in restless legs syndrome resolve after the administration of quinine (FDA Drug safety communication, 2010), a compound that reduces inhibitory activity ${ }^{68}$.

\section{The differentiation of clinical manifestations in neuromuscular and neurological diseases can be attributed to SI versus RI pathways}

The differentiation between SI and RI summarized in Table 3 can explain the three categories of fatal symptoms that arise in endstage neuromuscular and neurological diseases (Table 5). One striking observation from Table 5 is that both SI and RI can be attributed to fatal respiratory failure, the major cause of death among ALS patients. Overstimulation of SI pathways leads to 


\section{Table 5. The fatal symptom categories associated with neuromuscular and neurological diseases can be attributed to simple inhibition (SI) and/or recurrent inhibition (RI).}

\begin{tabular}{|c|c|c|c|c|c|c|c|c|}
\hline SI & RI & Fatal symptoms & 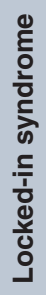 & $\frac{\infty}{4}$ & 믄 & 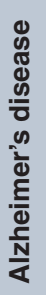 & 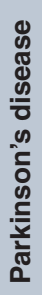 & 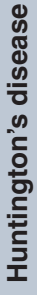 \\
\hline$\sqrt{ }$ & & Dysphagia-related malnutrition & & $\sqrt{ }$ & $\sqrt{ }$ & $\sqrt{ }$ & $\sqrt{ }$ & $\sqrt{ }$ \\
\hline$\sqrt{ }$ & & Dysphagia-related aspiration pneumonia & & $\sqrt{ }$ & $\sqrt{ }$ & $\sqrt{ }$ & $\sqrt{ }$ & $\sqrt{ }$ \\
\hline$\sqrt{ }$ & & Bowel dysfunction & & $\sqrt{ }$ & $\sqrt{ }$ & $\sqrt{ }$ & $\sqrt{ }$ & $\sqrt{ }$ \\
\hline$\sqrt{ }$ & & Bladder dysfunction & & $\sqrt{ }$ & $\sqrt{ }$ & $\sqrt{ }$ & $\sqrt{ }$ & $\sqrt{ }$ \\
\hline \multirow[t]{2}{*}{$\sqrt{ }$} & $\sqrt{ }$ & Respiratory malfunction & & $\sqrt{ }$ & & & & \\
\hline & $\sqrt{ }$ & Complete dysfunction of muscles involved in countering gravity & $\sqrt{ }$ & $\sqrt{ }$ & & & & \\
\hline
\end{tabular}

bowel dysfunction, bladder dysfunction, and dysphagia-related malnutrition and aspiration pneumonia; these symptoms are the major causes of death among patients with FTD, Alzheimer's disease, Parkinson's disease, and Huntington's disease. On the other hand, overstimulation of RI pathways can lead to end-stage locked-in syndrome.

Differential SI and RI involvement can also account for the wide variety of clinical manifestations in neuromuscular and neurological diseases during disease progression. As a group, neuromuscular and neurological diseases present with a wide spectrum of clinical manifestations (see Table 1), and stimulation of SI and/or RI pathways can account for this spectrum. For example, SI overstimulation can lead to FTD, Alzheimer's disease, Parkinson's disease, and Huntington's disease, whereas RI overstimulation can lead to locked-in syndrome. Finally, overstimulation of both the SI and RI pathways can lead to ALS.

Finally, the differentiation between SI and RI can help explain the differences in life expectancy among patients with various neuromuscular and neurological diseases. As discussed above, increased activity of both the SI and RI pathways leads to fatal respiratory depression (see Table 5), the principal cause of death in patients with ALS, the neuromuscular disease with the shortest life expectancy. Increased activity of either the SI or RI pathway-but not both — can also lead to respiratory depression, albeit not to direct fatal levels. Thus, patients with either SI or RI overstimulation generally live longer than patients with both SI and RI overstimulation. This coincides with the observation that patients with ALS - in which both the SI and RI pathways are overstimulated-have a shorter life expectancy than patients with FTD, Alzheimer's disease, Parkinson's disease, Huntington's disease, and locked-in syndrome, diseases in which either SI or RI activity is increased.

\section{Homeostatic interactions between inhibitory transmission and excitatory transmission}

Taken together, the wealth of observations discussed above suggest that the opposing excitatory and inhibitory systems may play a role in the pathogenesis of the same disease. This phenomenon has precedent, as inhibitory/excitatory homeostasis processes are also involved in seizure activity ${ }^{30,31}$. Neurons that receive excessive excitatory stimulation can subsequently become overstimulated by inhibitory transmission, and vice versa. This raises the intriguing question of which system in neuromuscular and neurological diseases is overstimulated first, and which system becomes overstimulated as a homeostatic response. This question has been addressed with respect to epileptic seizures ${ }^{30}$. With respect to neuromuscular and neurological diseases, it is important to note that the administration of glutamatergic excitatory compounds does not lead to the clinical manifestations summarized in Table 1; glutamatergic overstimulation can give rise to clinical manifestations only through excitotoxicity (i.e., overstimulation-induced neuronal cell death). However, inhibitory overstimulation can give rise to the clinical manifestations in Table 1 , even in the absence of neuronal cell death. Thus, I hypothesize that inhibitory overstimulation occurs first, and excitatory overstimulation is a homeostatic response. As inhibitory overstimulation increases, the excitatory system is stimulated further, until it reaches a level that induces neuronal cell death. This process is depicted schematically in Figure 2. Importantly, the order of the homeostatic process hypothesized here is precisely opposite to the homeostatic processes observed during epileptic seizures, in which excitatory overstimulation proceeds inhibitory overstimulation ${ }^{30}$.

\section{Other possible interpretations of these observations}

Other possible interpretations of the findings summarized in Table 1 should be considered. If inhibitory overstimulation plays a key role in neuromuscular and neurological diseases, one would 


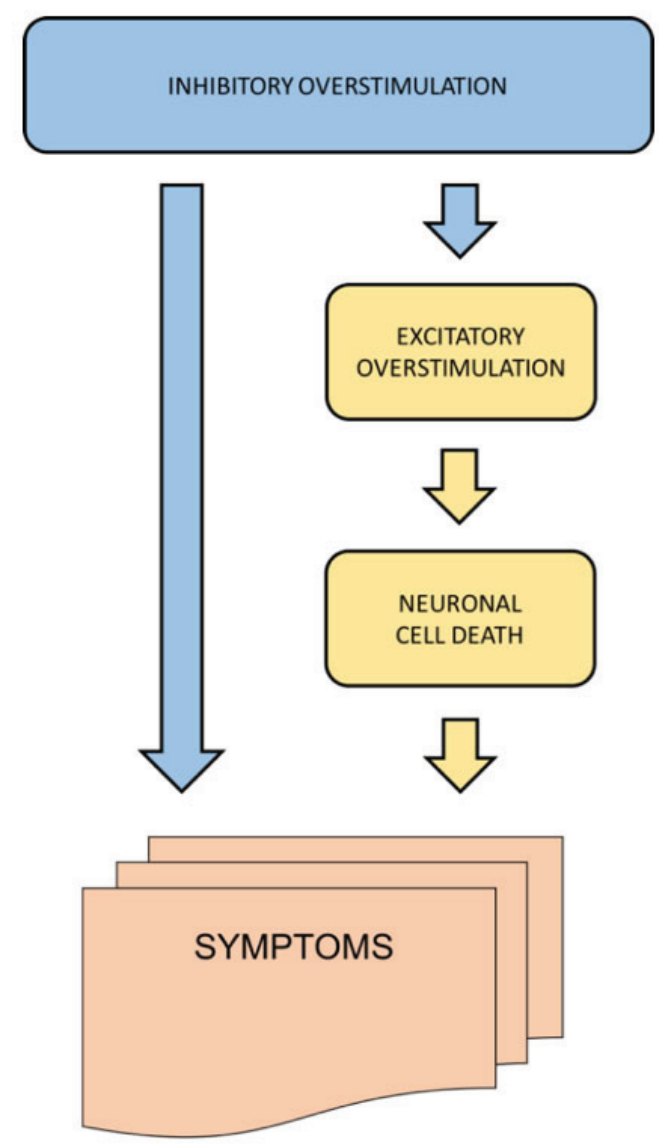

Figure 2. Schematic overview of glutamatergic overstimulation (yellow) and the inhibitory overstimulation hypothesis (blue and yellow). In the inhibitory overstimulation hypothesis, excitatory overstimulation is a homeostatic response to inhibitory overstimulation. A key feature of this model is that inhibitory overstimulation can be sufficient to cause symptoms (left blue arrow). As the disease progresses, increasing inhibitory overstimulation can eventually lead to excitatory overstimulation and neuronal cell death, making the symptoms irreversible.

expect these patients to present with sedation, thus indicating the possibility that physiological systems other than the inhibitory system may be involved. However, not all GABA receptor subtypes are involved in sedation ${ }^{69,70}$. Thus, inhibitory activity can occur without inducing pronounced sedation. This is supported by reports that benzodiazepine-induced dysphagia can occur even in non-sedated patients ${ }^{38-40}$. Second, the absence of seizures despite high glutamate levels could be due to a slow, but non-epileptogenic increase in glutamate levels during the progression of neuromuscular and neurological diseases. However, even small increases in glutamate levels can increase glutamatergic synchronization of a small subset of critical neurons, thereby leading to epileptic activity $^{30,31}$. Moreover, epileptic seizures are simply not reported among ALS patients, an observation that cannot be explained by a slow increase in glutamate levels, as glutamate does not cause inhibitory activity ${ }^{22-29}$. Furthermore, slow increasing levels of glutamate in the absence of seizure activity may reflect the involvement of an inhibitory homeostatic process ${ }^{30,31}$. Finally, the differentiation between SI and RI depicted in Table 4 and Table 5 may be attributed to the involvement of neuronal pathways projecting to either voluntary or involuntary muscles. However, this cannot explain split-hand syndrome in ALS patients or rest tremors in Parkinson's disease, as these phenomena involve only voluntary muscles. Moreover, split-hand syndrome involves identically innervated muscles that cannot be differentiated by any aspect other than SI/RI innervation.

Therapeutic potential for targeting inhibitory activity From a clinical perspective, an important consequence that emerges from the inhibitory overstimulation hypothesis is that the clinical manifestations summarized in Table 1 develop before neurons have undergone cell death. The implication of this possibility is that decreasing inhibitory activity may be beneficial in terms of slowing-or even preventing - the progression of neuromuscular and neurological diseases. Compounds that can reduce inhibitory activity are currently available; unfortunately, however, these compounds can induce seizure activity and are therefore not used therapeutically. Nevertheless, their potential for preventing the pathogenesis of neuromuscular and neurological diseases suggests that compounds that target the inhibitory system could be developed for clinical applications. For example, the average life expectancy of a patient with ALS is 3-5 years after onset, and most neuromuscular and neurological diseases are severe and ultimately fatal. With respect to Alzheimer's disease and Parkinson's disease, dysphagia and respiratory depression-related aspiration pneumonia are the most common causes of death ${ }^{16,17}$. Neuromuscular diseases also present with the severe and potential fatal clinical manifestations listed in Table $1 ;^{1-7,9-11,13,15,17-21}$ thus, the ability to prevent these symptoms could significantly prolong the life expectancy of these patients. From a treatment perspective, it is interesting to note that the selective GABA antagonist SGS-742 has been shown to be both clinically feasible and safe $^{52}$.

\section{Conclusions and future perspectives}

Based upon the plethora of observations regarding the inhibitory system, I hypothesize that this system plays an important role in the pathogenesis of both neuromuscular and neurological diseases. Importantly, overstimulation of the inhibitory system can explain both the absence of epileptic seizures despite the elevated glutamate levels and the pharmacological induction of symptoms present in patients with neuromuscular and neurological diseases. Moreover, the separation between SI and RI can account for the various categories of clinical manifestations observed in these patients. Specifically, I hypothesize that increased glutamate levels in neuromuscular and neurological diseases are actually a homeostatic response to an overstimulated inhibitory system. Implicating the inhibitory system in the pathogenesis of neuromuscular and neurological diseases is highly relevant, given that the majority of 
approaches being developed for treating these diseases focus on reducing glutamatergic activity, rather than reducing inhibitory activity. Moreover, this putative connection between the inhibitory system and neuromuscular/neurological diseases may have longreaching implications, including the need to develop therapies designed to reduce inhibitory overstimulation in neuromuscular and neurological patients.

\section{Author contributions}

BT conceived the study, performed the analysis, and wrote the paper.

\section{Competing interests}

BT has filed a patent application on the treatment of neuromuscular and neurologic diseases with therapies that reduce inhibitory overstimulation, and founded Ry Pharma, a company that aims to develop such therapies.

Grant information

The author(s) declared that no grants were involved in supporting this work.

\section{Acknowledgements}

The author wishes to thank Dr. H. Jousma, Prof. Dr. A.F. Cohen and Prof. Dr. D.D. Breimer for their critical review of the manuscript.
1. Standifer: Handbook of disabilities, neuromuscular disorders, RCEP7, University of Missouri, 2014

2. Kiernan MC, Vucic S, Cheah BC, et al:: Amyotrophic lateral sclerosis. Lancet. 2011; 377(9769): 942-55 PubMed Abstract | Publisher Full Text

3. Silani V, Messina S, Poletti B, et al.: The diagnosis of Amyotrophic latera sclerosis in 2010. Arch Ital Biol. 2011; 149(1): 5-27. PubMed Abstract | Publisher Full Text

4. Turner MR, Hardiman O, Benatar M, et al.: Controversies and priorities in amyotrophic lateral sclerosis. Lancet Neurol. 2013; 12(3): 310-22. PubMed Abstract | Publisher Full Text | Free Full Text

5. Achi EY, Rudnicki SA: ALS and Frontotemporal Dysfunction: A Review. Neurol Res Int. 2012; 2012: 806306.

PubMed Abstract | Publisher Full Text | Free Full Text

6. Zago S, Poletti B, Morelli C, et al:: Amyotrophic lateral sclerosis and frontotemporal dementia (ALS-FTD). Arch Ital Biol. 2011; 149(1): 39-56. PubMed Abstract | Publisher Full Text

7. Ringholz GM, Appel SH, Bradshaw M, et al:: Prevalence and patterns of cognitive impairment in sporadic ALS. Neurology. 2005; 65(4): 586-90. PubMed Abstract | Publisher Full Text

8. Warren JD, Rohrer JD, Rossor MN: Clinical review. Frontotemporal dementia. BMJ. 2013; 347: f4827.

PubMed Abstract | Publisher Full Text | Free Full Text

9. Tartaglia MC, Rowe A, Findlater K, et al.: Differentiation between primary lateral sclerosis and amyotrophic lateral sclerosis: examination of symptoms and signs at disease onset and during follow-up. Arch Neurol. 2007; 64(2): 232-6. PubMed Abstract | Publisher Full Text

10. Singer MA, Statland JM, Wolfe Gl, et al.: Primary lateral sclerosis. Muscle Nerve. 2007; 35(3): 291-302.

PubMed Abstract | Publisher Full Text

11. Kalia LV, Lang AE: Parkinson's disease. Lancet. 2015; 386(9996): 896-912.

PubMed Abstract | Publisher Full Text

12. Alves L, Correia AS, Miguel R, et al:: Alzheimer's disease: a clinical practice-oriented review. Front Neurol. 2012; 3: 63. pubMed Abstract | Publisher Full Text | Free Full Text

13. Roos RA: Huntington's disease: a clinical review. Orphanet J Rare Dis. 2010; 5. 40 .

PubMed Abstract | Publisher Full Text | Free Full Text

14. Spencer D: Seizures and epileptiform activity in early Alzheimer disease: how hard should we be looking? Epilepsy Curr. 2014; 14(2): 73-75. PubMed Abstract | Publisher Full Text | Free Full Text

15. Martino D, Stamelou M, Bhatia KP: The differential diagnosis of Huntington's disease-like syndromes: 'red flags' for the clinician. J Neurol Neurosurg Psychiatry. 2013; 84(6): 650-656.

PubMed Abstract | Publisher Full Text | Free Full Text

16. Kalia M: Dysphagia and aspiration pneumonia in patients with Alzheimer's disease. Metabolism. 2003; 52(10 Suppl 2): 36-8. PubMed Abstract | Publisher Full Text

17. Tjaden K: Speech and Swallowing in Parkinson's Disease. Top Geriatr Rehabil.
2008; 24(2): 115-126

PubMed Abstract | Publisher Full Text | Free Full Text

18. Cohen B, Caroscio J: Eye movements in amyotrophic lateral sclerosis. J Neural Transm Suppl. 1983; 19: 305-15.

PubMed Abstract

19. Panicker JN, Fowler CJ, Kessler TM: Lower urinary tract dysfunction in the neurological patient: clinical assessment and management. Lancet Neurol. 2015; 14(7): 720-32.

PubMed Abstract | Publisher Full Text

20. Toepfer M, Folwaczny C, Klauser A, et al: Gastrointestinal dysfunction in amyotrophic lateral sclerosis. Amyotroph Lateral Scler Other Motor Neuron Disord. 1999; 1(1): 15-9.

PubMed Abstract | Publisher Full Text

21. Fasano A, Visanji NP, Liu LW, et al:: Gastrointestinal dysfunction in Parkinson's disease. Lancet Neurol. 2015; 14(6): 625-39.

PubMed Abstract | Publisher Full Text

22. Rothstein JD, Tsai G, Kuncl RW, et al.: Abnormal excitatory amino acid metabolism in amyotrophic lateral sclerosis. Ann Neurol. 1990; 28(1): 18-25. PubMed Abstract | Publisher Full Text

23. Spreux-Varoquaux O, Bensimon G, Lacomblez L, et al:: Glutamate levels in cerebrospinal fluid in amyotrophic lateral sclerosis: a reappraisal using a new HPLC method with coulometric detection in a large cohort of patients. $J$ NeurO Sci. 2002; 193(2): 73-78. PubMed Abstract | Publisher Full Text

24. Olney JW: Neurotoxicity of excitatory amino acids. In: E.G. McGeer, J.W. Olney, P.L. McGeer (Eds.), Kainic Acid as a Tool in Neurobiology, Raven Press, New York, 1978; 95-121.

25. Coyle JT, Puttfarcken P: Oxidative stress, glutamate, and neurodegenerative disorders. Science. 1993; 262(5134): 689-695. PubMed Abstract | Publisher Full Text

26. Kim AH, Kerchner GA, Choi DW: Blocking Excitotoxicity or Glutamatergic Storm. Chapter 1 in CNS Neuroprotection. Marcoux FW and Choi DW, editors. Springer, New York. 2002; 3-36. Reference Source

27. Lipton SA, Rosenberg PA: Excitatory amino acids as a final common pathway for neurologic disorders. N Engl J Med. 1994; 330(9): 613-622. PubMed Abstract | Publisher Full Text

28. Doble A: The role of excitotoxicity in neurodegenerative disease: implications for therapy. Pharmacol Ther. 1999; 81(3): 163-221. PubMed Abstract | Publisher Full Text

29. Dong XX, Wang Y, Qin ZH: Molecular mechanisms of excitotoxicity and their relevance to pathogenesis of neurodegenerative diseases. Acta Pharmacol Sin. 2009; 30(4): 379-87.

PubMed Abstract | Publisher Full Text | Free Full Text

30. During MJ, Spencer DD: Extracellular hippocampal glutamate and spontaneous seizure in the conscious human brain. Lancet. 1993; 341(8861): 1607-10. PubMed Abstract | Publisher Full Text

31. Chamberlin NL, Traub RD, Dingledine R: Role of EPSPs in initiation of spontaneous synchronized burst firing in rat hippocampal neurons bathed in high potassium. J Neurophysiol. 1990; 64(3): 1000-8. PubMed Abstract 


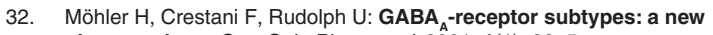
pharmacology. Curr Opin Pharmacol. 2001; 1(1): 22-5. PubMed Abstract | Publisher Full Text

33. Rudolph U, Knoflach F: Beyond classical benzodiazepines: Novel therapeutic potential of GABA ${ }_{A}$ receptor subtypes. Nat Rev Drug Discov. 2011; 10(9): 685-697.

PubMed Abstract | Publisher Full Text | Free Full Text

34. Forster A, Gardaz JP, Suter PM, et al:: Respiratory depression by midazolam and diazepam. Anesthesiology. 1980; 53(6): 494-7.

PubMed Abstract | Publisher Full Text

35. Wall BT, Dirks ML, Snijders T, et al:: Substantial skeletal muscle loss occurs during only 5 days of disuse. Acta Physiol (Oxf). 2014; 210(3): 600-11. PubMed Abstract | Publisher Full Text

36. Sullivan EV, Pfefferbaum A: Alcohol and the Nervous System: Handbook of Clinical Neurology. Edited Edith V. Sullivan \& Adolf Pfefferbaum. ISBN9780444626226. 2014: 95-96.

37. Hockman $\mathrm{CH}$, Weerasuriya $\mathrm{A}$, Bieger D: GABA receptor-mediated inhibition of reflex deglutition in the cat. Dysphagia. 1996; 11(3): 209-215. PubMed Abstract | Publisher Full Text

38. Wyllie E, Wyllie R, Cruse RP, et al:: The mechanism of nitrazepam-induced drooling and aspiration. N Engl J Med. 1986; 314(1): 35-8. PubMed Abstract | Publisher Full Text

39. Buchholz D, Jones B, Neumann S, et al:: Benzodiazepine-induced pharyngeal dysphagia: a report of two probable cases. Dysphagia. 1995; 10(2): 142-6.

40. Dantas RO, Nobre Souza MA: Dysphagia induced by chronic ingestion of benzodiazepine. Am J Gastroenterol. 1997; 92(7): 1194-6. PubMed Abstract

41. Dua KS, Surapaneni SN, Santharam R, et al.: Effect of systemic alcohol and nicotine on airway protective reflexes. Am J Gastroenterol. 2009; 104(10): 2431-8. PubMed Abstract | Publisher Full Text | Free Full Text

42. Van Steveninck AL, Mandema JW, Tuk B, et al.: A comparison of the concentrationeffect relationships of midazolam for EEG-derived parameters and saccadic peak velocity. Br J Clin Pharmacol. 1993; 36(2): 109-115. PubMed Abstract | Publisher Full Text | Free Full Text

43. Benson PJ, Beedie SA, Shephard E, et al:: Simple viewing tests can detect eye movement abnormalities that distinguish schizophrenia cases from controls with exceptional accuracy. Biol Psychiatry. 2012; 72(9): 716-24. PubMed Abstract | Publisher Full Text

44. Iyer PM, Egan C, Pinto-Grau M, et al.: Functional Connectivity Changes in Resting-State EEG as Potential Biomarker for Amyotrophic Lateral Sclerosis. PLoS One. 2015; 10(6): e0128682.

PubMed Abstract | Publisher Full Text | Free Full Text

45. Igawa $Y$, Mattiasson A, Andersson KE: Effects of GABA-receptor stimulation and blockade on micturition in normal rats and rats with bladder outflow obstruction. J Urol. 1993; 150(2 Pt 1): 537-42. PubMed Abstract

46. Andersson KE, Wein AJ: Pharmacology of the lower urinary tract: basis for current and future treatments of urinary incontinence. Pharmacol Rev. 2004 56(4): 581-631.

PubMed Abstract | Publisher Full Text

47. Hyland NP, Cryan JF: A Gut Feeling about GABA: Focus on GABA B $_{B}$ Receptors Front Pharmacol. 2010; 1: 124

PubMed Abstract | Publisher Full Text | Free Full Text

48. Krantis A: GABA in the Mammalian Enteric Nervous System. News Physiol Sci. 2000; 15: 284-290. PubMed Abstract

49. Oslin D, Atkinson RM, Smith DM, et al:: Alcohol related dementia: proposed clinical criteria. Int J Geriatr Psychiatry. 1998; 13(4): 203-212. PubMed Abstract | Publisher Full Text

50. Billioti de Gage S, Bégaud B, Bazin F, et al:: Benzodiazepine use and risk of dementia: prospective population based study. BMJ. 2012; 345(2012): e6231. PubMed Abstract | Publisher Full Text | Free Full Text

51. Bell GD, Spickett GP, Reeve PA, et al:: Intravenous midazolam for upper gastrointestinal endoscopy: a study of 800 consecutive cases relating dose to age and sex of patient. Br J Clin Pharmacol. 1987; 23(2): 241-243. PubMed Abstract | Publisher Full Text | Free Full Text

52. Froestl W, Gallagher M, Jenkins $\mathrm{H}$, et al.: SGS742: the first GABA ${ }_{B}$ receptor antagonist in clinical trials. Biochem Pharmacol. 2004; 68(8): 1479-87. PubMed Abstract | Publisher Full Text

53. Martínez-Cué C, Delatour B, Potier MC: Treating enhanced GABAergic inhibition in Down syndrome: Use of GABA $\alpha 5$-selective inverse agonists. Neurosci Biobehav Rev. 2014; 46(Pt 2): 218-227. PubMed Abstract | Publisher Full Tex

54. Wu Z, Guo Z, Gearing M, et al:: Tonic inhibition in dentate gyrus impairs longterm potentiation and memory in an Alzheimer's [corrected] disease model. Nat Commun. 2014; 5: 4159 .

PubMed Abstract | Publisher Full Text | Free Full Text

55. Miller RG, Moore DH 2nd, Gelinas DF, et al:: Phase III randomized trial of gabapentin in patients with amyotrophic lateral sclerosis. Neurology. 2001; 56(7): 843-848. PubMed Abstract

56. Cudkowicz ME, Shefner JM, Schoenfeld DA, et al:: A randomized, placebocontrolled trial of topiramate in amyotrophic lateral sclerosis. Neurology. 2003 61(4): 456-464.

PubMed Abstract | Publisher Full Text

57. Gordon PH, Moore DH, Miller RG, et al:: Efficacy of minocycline in patients with amyotrophic lateral sclerosis: a phase III randomised trial. Lancet Neurol. 2007; 6(12): 1045-53.

PubMed Abstract | Publisher Full Text

58. Ahmadirad N, Shojaei A, Javan M, et al:: Effect of minocycline on pentylenetetrazol-induced chemical kindled seizures in mice. Neurol Sci. 2014; 35(4): 571-6.

PubMed Abstract | Publisher Full Text

59. Elia AE, Lalli S, Monsurrò MR, et al:: Tauroursodeoxycholic acid in the treatment of patients with amyotrophic lateral sclerosis. Eur J Neurol. 2016; 23(1): 45-52. PubMed Abstract | Publisher Full Text

60. Yanovsky $Y$, Schubring SR, Yao $Q$, et al.: Waking action of ursodeoxycholic acid (UDCA) involves histamine and GABA ${ }_{A}$ receptor block. PLoS One. 2012; 7(8): e42512.

PubMed Abstract | Publisher Full Text | Free Full Text

61. Windhorst U: On the role of recurrent inhibitory feedback in motor control. Prog Neurobiol. 1996; 49(6): 517-87.

PubMed Abstract | Publisher Full Text

62. Lipski J, Fyffe RE, Jodkowski J: Recurrent inhibition of cat phrenic motoneurons. J Neurosci. 1985; 5(6): 1545-55.

PubMed Abstract

63. McCoy T: How Stephen Hawking, diagnosed with ALS decades ago, is still alive. Washington Post, February 24, 2015. accessed May 10, 2016. Reference Source

64. Eisen A, Kuwabara S: The split hand syndrome in amyotrophic lateral sclerosis. J Neurol Neurosurg Psychiatry. 2012; 83(4): 399-403.

PubMed Abstract | Publisher Full Text

65. Napier JR: The prehensile movements of the human hand. J Bone Joint Surg Br. 1956; 38-B(4): 902-913.

PubMed Abstract

66. Rossi A, Mazzocchio R: Renshaw recurrent inhibition to motoneurones innervating proximal and distal muscles of the human upper and lower limbs. In: Muscle Afferents and Spinal Control of Movement, Eds L. Jami, E. PierrotDeseilligny and D Zytnicki. Pergamon Press: Oxford. 1992; 313-319.

67. Helmich RC, Hallett M, Deuschl G, et al.: Cerebral causes and consequences of parkinsonian resting tremor: a tale of two circuits? Brain. 2012; 135(Pt 11): 3206-26.

PubMed Abstract | Publisher Full Text | Free Full Text

68. Amabeoku GJ, Chikuni O: Effects of some GABAergic agents on quinineinduced seizures in mice. Experientia. 1992; 48(7): 659-62. PubMed Abstract | Publisher Full Text

69. McKernan RM, Rosahl TW, Reynolds DS, et al:: Sedative but not anxiolytic properties of benzodiazepines are mediated by the GABA(A) receptor alpha1 subtype. Nat Neurosci. 2000; 3(6): 587-92. PubMled Abstract | Publisher Full Text

70. Reynolds DS, Rosahl TW, Cirone J, et al.: Sedation and anesthesia mediated by distinct GABA(A) receptor isoforms. J Neurosci. 2003; 23(24): 8608-17. PubMed Abstract 


\section{Open Peer Review}

\section{Current Peer Review Status:}

\section{Version 1}

Reviewer Report 10 August 2016

https://doi.org/10.5256/f1000research.9443.r15213

(c) 2016 de Vos W. This is an open access peer review report distributed under the terms of the Creative Commons Attribution License, which permits unrestricted use, distribution, and reproduction in any medium, provided the original work is properly cited.

\section{Willem M de Vos}

Laboratory of Microbiology, Wageningen University, Wageningen, The Netherlands

The opinion paper by Tuk provides an overview of the inhibitory system involved in neural signal transduction. Based on an extensive review of the literature the author provides a number of challenging but well-reasoned hypotheses about the impact of this system on both neuromuscular and neurological diseases. This potential connection may have important implications for the understanding and future treatment of these so far (almost) untreatable diseases.

Only few minor points should be addressed.

1. The use of the term 'inhibitory system' is somewhat confusing - the context is often not specified (inhibitory system of what...) although the author means neural signal transduction - however, this should be mentioned where relevant and certainly in the title.

2. The link between GABA production by intestinal bacteria and gut GABA receptor stimulation could be further addressed as it provides a way how other factors such as food or the gut microbiome may modulate GABA response (see also reference 47 and later work of these authors like Bravo et al. (2011).

3. The literature is well reviewed and the paper is supported by 5 useful Tables, 2 clear Figures and 70 references of peer reviewed papers - the one Washington Post article may be better mentioned in the text.

\section{References}

1. Bravo JA, Forsythe $P$, Chew MV, Escaravage $E$, et al.: Ingestion of Lactobacillus strain regulates emotional behavior and central GABA receptor expression in a mouse via the vagus nerve.Proc Natl Acad Sci U S A. 2011; 108 (38): 16050-5 PubMed Abstract | Publisher Full Text 
Competing Interests: No competing interests were disclosed.

I confirm that I have read this submission and believe that I have an appropriate level of expertise to confirm that it is of an acceptable scientific standard.

Reviewer Report 05 August 2016

https://doi.org/10.5256/f1000research.9443.r15214

(c) 2016 Hoogstraate J. This is an open access peer review report distributed under the terms of the Creative Commons Attribution License, which permits unrestricted use, distribution, and reproduction in any medium, provided the original work is properly cited.

\section{Janet Hoogstraate}

1 Valneva Sweden AB, Stockholm, Sweden

2 Stockholm Brain Institute, Stockholm, Sweden

The manuscript by B.Tuk provides a comprehensive and up-to-date review of the clinical observations of neurodegenerative diseases relevant to the discussion on pathogenesis. The methodology of linking the clinical observations to a common pathology that is different in sequence of events compared to other scientific literature is sound. The data and the proposed theory are presented in a suitable manner.

The position that there is an absence of elevated seizure activity in all 8 of the neurological and neuromuscular diseases should be revised to my opinion. While this can be said for ALS, there is substantial epidemiological data to support an higher frequency of epileptic seizures in the early stages of Alzheimer's Disease (ref 1-5). Based on the enormous increase of glutamate levels in ALS patients and the absence of elevated risk for epileptic activity in that population, there is still good support for postulating the theory of the inhibitory system as a plausible trigger for these diseases, but I propose that that section of the article and Table 1 be revised to reflect that nuance.

I recommend that the article be indexed, with the minor revision outlined above.

\section{References}

1. Imfeld $P$, Bodmer $M$, Schuerch M, Jick SS, et al.: Seizures in patients with Alzheimer's disease or vascular dementia: a population-based nested case-control analysis.Epilepsia. 2013; 54 (4): 700-7 PubMed Abstract | Publisher Full Text

2. Gaitatzis A, Carroll K, Majeed A, W Sander J: The epidemiology of the comorbidity of epilepsy in the general population.Epilepsia. 2004; 45 (12): 1613-22 PubMed Abstract | Publisher Full Text 3. Friedman D, Honig LS, Scarmeas N: Seizures and epilepsy in Alzheimer's disease.CNS Neurosci Ther. 2012; 18 (4): 285-94 PubMed Abstract | Publisher Full Text

4. Scarmeas N, Honig LS, Choi H, Cantero J, et al.: Seizures in Alzheimer disease: who, when, and how common?. Arch Neurol. 2009; 66 (8): 992-7 PubMed Abstract | Publisher Full Text 5. Amatniek JC, Hauser WA, DelCastillo-Castaneda C, Jacobs DM, et al.: Incidence and predictors of seizures in patients with Alzheimer's disease.Epilepsia. 2006; 47 (5): 867-72 PubMed Abstract | Publisher Full Text 
Competing Interests: No competing interests were disclosed.

I confirm that I have read this submission and believe that I have an appropriate level of expertise to confirm that it is of an acceptable scientific standard.

The benefits of publishing with F1000Research:

- Your article is published within days, with no editorial bias

- You can publish traditional articles, null/negative results, case reports, data notes and more

- The peer review process is transparent and collaborative

- Your article is indexed in PubMed after passing peer review

- Dedicated customer support at every stage

For pre-submission enquiries, contact research@f1000.com 